\title{
Three-dimensional measurement and cohesive element modelling of deformation and damage in a 2.5-dimensional woven Ceramic Matrix Composite
}

\author{
Luis Saucedo-Mora ${ }^{\mathrm{a}}$, Chunrong Zou ${ }^{\mathrm{b}}$, Tristan Lowe ${ }^{\mathrm{c}}$ and T. James Marrow *d \\ a: Institute Eduardo Torroja for Construction Sciences-CSIC, Madrid, Spain \\ b: National University of Defense Technology, Changsha, China \\ c: Henry Moseley Imaging Centre, University of Manchester, UK \\ d: Department of Materials, University of Oxford, Oxford UK
}

*Corresponding Author: e-mail: james.marrow@materials.ox.ac.uk

\begin{abstract}
A cohesive element numerical model, which reproduces the three-dimensional microstructure of a 2.5-dimensional Silicon-Nitrogen-Oxide fibre/fabric reinforced Boron Nitride ceramic matrix composite (SiNO/BN) is applied to simulate the failure of specimens that are observed in situ during diametral compression testing. Measurements of deformation by image correlation of 2dimensional optical surface observations and 3-dimensional X-ray computed tomographs are used to fit the simulation's elastic properties for the matrix and fibre tows. The observed patterns of damage nucleation and propagation are correctly simulated using a local tensile strain criterion.
\end{abstract}

Keywords: Ceramic-matrix composites (CMCs); Mechanical properties; Finite element analysis (FEA); Digital Image Correlation; Computed Tomography 


\section{Nomenclature:}

DIC Digital Image Correlation

DVC Digital Volume Correlation

D matrix relating stress and strain

E $\quad$ Young's modulus

FE Finite Element

FEMME Finite Element Microstructure MEshfree

fps frames per second

PIP Polymer Infiltration and Pyrolysis

XCT X-ray Computed Tomography

a parameter for the horizontal fibre tow position

$b \quad$ parameter for the fibre tow thickness

$c \quad$ parameter for the vertical fibre tow $y$-position

$P \quad$ load

$R \quad$ radius

$t \quad$ thickness

$x, y, z$ orthogonal axes and coordinates

$x_{1}, x_{2}, x_{3}, x_{4} \quad$ functions of $x$-coordinates that define nodes of the fibre tows

$\alpha \quad$ semi-contact angle

$\varepsilon \quad$ strain

$\mathcal{E}_{\square \text { rit }} \quad$ critical tensile strain

$\varepsilon_{f} \quad$ final tensile strain

$\sigma \quad$ stress

$\sigma_{\square} \quad$ tensile strength 


\section{Introduction}

Continuous fibre reinforced ceramic quasi-brittle composites are promising candidate materials for structural and functional applications at high temperatures. For example, fibrereinforced $\mathrm{SiC}-\mathrm{SiC}$ composites have been proposed in fusion and advanced fission power reactors ${ }^{1,2}$ and SiNO fibre-reinforced Boron Nitride (SiNO-BN) composites are potential high temperature materials with transparency to electromagnetic radiation ${ }^{3-5}$. There is a need to assess the mechanical integrity of these quasi-brittle materials, and to predict their performance under different states of loading. Continuum-mechanics methods can be inadequate, as they may not take into account the effects of the heterogeneous fabric architecture on the strain distribution that develops within the composite microstructure ${ }^{6}$. The strain distributions in woven fibre reinforced composites are influenced by factors that include the orientation of the fibre tow with respect to the loading axis ${ }^{7}$, the arrangement and structure of neighbouring tows, matrix and pores ${ }^{8}$, and also the mechanical properties of the composite's constituents ${ }^{9}$.

Numerical modelling may simulate the behaviour of structural components that are made of ceramic composites ${ }^{10}$. Ideally, models need to reproduce explicitly the large-scale component and its microstructure, but high fidelity Finite Element models can be very computationally expensive. One solution is to coarsen the mesh and consider a material with anisotropic mechanical properties ${ }^{11}$. However, this approach may not be used to study the local processes of damage coalescence and fracture in the microstructure. Multiscale models address this via local insertion of the microstructure into a coarser FE mesh ${ }^{10,12,13}$. As an example, the FEMME model for quasi-brittle materials ${ }^{14}$ uses the microstructure as a local enrichment of a coarse cohesive FE mesh. This computationally efficient approach has been applied to simulate damage development in a range of quasi-brittle materials including $\mathrm{SiC}$ $\mathrm{SiC}$ composites ${ }^{15}$ and thermal barrier coatings ${ }^{16}$. Cohesive FE models can be used with the mesh adapted to key features of the microstructure such as the composite plies ${ }^{17}$ and some models represent each tow of fibres explicitly ${ }^{18}$.

This paper presents a novel example of cohesive element modelling, derived from 3D characterization of microstructure by high-resolution X-ray computed tomography. We examine a 2.5D Silicon Nitrogen Oxide fibre/fabric reinforced Boron Nitride composite (2.5D $\left.\mathrm{SiNO}_{\mathrm{f}} / \mathrm{BN}\right)$. The simulation of deformation and damage is compared with data obtained through Digital Image Correlation (DIC) of optical observations and Digital Volume Correlation (DVC) of laboratory X-ray computed tomographs to derive the criteria for damage nucleation. Digital image correlation (DIC) is a displacement measurement method 19 that tracks the movements within successive images; it is well suited to the detection of damage ${ }^{20}$ and has been applied previously to study deformation and damage of ceramic composites ${ }^{21}$. X-ray computed tomography (XCT) can be used to observe damage development within materials, including composites ${ }^{15,22}$. It can be combined with threedimensional digital volume correlation ${ }^{23}$ to measure the displacements within the test specimen that arise from deformation and damage ${ }^{15,24,25}$. 


\section{Experimental Methods}

\subsection{Material and sample preparation}

The preform of SiNO fibres, fabricated at the National University of Defence Technology (Changsha, China), was woven by the Changzhou Bolong Aerospace Technology Corp. (Jiangsu, China). Its 2.5 dimensional $(2.5 \mathrm{D})$ architecture is illustrated in Fig 1. The wavelike warp tows (tow specifications: 300 fibres/tow, aligned in the $y$-direction) introduce a favorable shear tolerance in the thickness direction, while the straight weft tows (also 300 fibres/tow, aligned in the $z$-direction) pass directly through the warp tow layer (Fig 1a). The $2.5 \mathrm{D}$ structure is formed by joining woven $2 \mathrm{D}$ layers (warp) with the weft tows. The fabric was slightly compressed in the $z$-direction to maintain its architecture during fabrication.

The $\mathrm{SiNO}_{\mathrm{f}} / \mathrm{BN}$ composite was prepared by the PIP method (Polymer Infiltration and Pyrolysis) using vacuum-assisted infiltration of liquid borazine as the precursor for the matrix ${ }^{26}$. Cross-linking and consolidation of the precursor was conducted at $90^{\circ} \mathrm{C}$, with an initial $\mathrm{N}_{2}$ pressure of $3 \mathrm{MPa}$. The solid preform was pyrolysed in 2 cycles, at $1000{ }^{\circ} \mathrm{C}$ and $1200{ }^{\circ} \mathrm{C}$ for $1 \mathrm{~h}$ under at $\mathrm{N}_{2}$ atmosphere $(0.1 \mathrm{MPa})$, to prevent the matrix from oxidizing during the ceramic conversion. With three cycles of infiltration and pyrolysis, the final composite was obtained with a density of $1.85 \mathrm{~g} / \mathrm{cm}^{3}$, which corresponds to a relative density of $91.2 \%$, and an open porosity (e.g. Fig 1b) of $7.5 \%$ measured by the Archimedes method. Fig 1c shows a laboratory tomograph of a significant volume of the sample obtained in this work, and its segmented macro-porosity is shown in Fig 1d.

In the fabricated composite, the warp fibre tows have an average amplitude of $0.79 \mathrm{~mm}$ and a wavelength of $6.3 \mathrm{~mm}$ in the $x-y$ plane. The fibre content of the composite was $\sim 40 \%$ by volume. The matrix material is distributed mainly between the fibres of the warp tows in regions where they do not cross the weft tow fibres; here the material was less compressed during the manufacturing process ${ }^{27}$. The mechanical properties of the fibres, matrix and bulk composite (tested in flexure with the tensile stress parallel to the weft fibres) are summarised in Table 1.

The test specimens (Fig 2a) were prepared from an as-manufactured composite sheet that was $28.8 \mathrm{~mm}$ thick ( $y$-direction). After slicing with a $1 \mathrm{~mm}$ width saw, a $25 \mathrm{~mm}$ diameter core drill was used to cut a cylindrical specimen with a diameter of $22.7 \mathrm{~mm}$ ( $x-y$ plane) and a thickness of $4.1 \mathrm{~mm}$ (z-direction); both cuts were done with water lubrication. The specimens were ultrasonically cleaned in water after cutting. No further surface preparation was done. Each specimen has four warp tow layers along the $z$-direction while the circular cross-section is approximately 1.5 times the warp tow wavelength and contains 3 columns of weft tows in the $x-y$ plane.

\subsection{Mechanical Testing}

The experiment was designed to investigate the criteria for tensile damage using in situ observation. The diametral compression specimen geometry was chosen as it allows the surface deformation to be observed in situ optically, and is also quite suitable for in situ X-ray computed tomography. A tensile stress in the $x$ direction was induced by applying a compressive load in the vertical $y$ direction; the ratio of compressive to tensile stress is approximately $3: 1$ at the centre of the specimen ${ }^{28}$. Shaped steel anvils were used to reduce 
the contact pressure. To induce tensile failures successfully in brittle materials requires an anvil contact angle exceeding 0.27 radians ${ }^{28}$. Considering Hertzian contact mechanics and the composite's bulk elastic properties, the anvil radius was chosen to be $13.8 \mathrm{~mm}$ to obtain a semi-contact angle of approximately 0.30 radians. The experimental set-up of the diametral compressive test is shown in Fig 2a, which also illustrates the coordinate system and loading direction.

Optical imaging and laboratory X-ray computed tomography were used to observe independent tests. The optically examined specimens were loaded progressively under displacement control until failure, using a Shimadzu loading frame with a $10 \mathrm{kN}$ load cell at a crosshead speed of $0.1 \mathrm{~mm} /$ minute. The optical observations were recorded simultaneously using a CCD camera with an acquisition speed of $0.5 \mathrm{fps}$ (frames per second); the raw 8-bit grey-scale images have a size of $2048 \times 2048$ pixels at a pixel size equivalent to $11.76 \mu \mathrm{m}$.

The X-ray computed tomography observations were carried out using a Nikon Custom Bay instrument operating at $130 \mathrm{kV}$ energy. The load was applied using a Deben $20 \mathrm{kN}$ loading rig equipped with a Perspex tube that is transparent to X-rays (Fig 2b); although transparent to visible light, the loading rig does not permit simultaneous optical observation of the test specimen surface. The tomographed specimen was loaded in displacement control, from a preload of $20 \mathrm{~N}$ to a maximum of $1 \mathrm{kN}$; the sample was not tested to failure and observations were obtained at $20 \mathrm{~N}, 600 \mathrm{~N}, 800 \mathrm{~N}$ and $1000 \mathrm{~N}$. At each observation, the displacement was maintained while a tomograph was recorded. Each tomograph was reconstructed from approximately 3000 radiographs via standard back-projection methods using the Nikon software. The tomographs were cropped to a volume of interest of $2000 \times 2000 \times 1222$ pixels, with an 8-bit grey-scale intensity range. The tomograph voxel size is $19.8 \mu \mathrm{m}$, due to the sample to detector distance imposed by the loading rig.

\subsection{Image Correlation Analysis.}

Displacements in the $x-y$ plane were measured via digital image correlation (DIC) analysis of the optical observations of the specimen surface, using the LaVision Davis 8.2.2. Strainmaster software. An analysis of rigid body translations $(\sim 100 \mu \mathrm{m})$ of an unloaded specimen found that for an interrogation subset size of $128 \times 128$ pixels (overlap $75 \%$ with two passes) the displacement measurement uncertainty is $0.32 \mu \mathrm{m}$, measured as the standard deviation of the displacement vector magnitudes. The corresponding strain error obtained from the gradients of the measured displacement field is $3.0 \times 10^{-5}$. The X-ray tomographs were analysed by digital volume correlation (DVC), also using the LaVision Davis 8.2.2. Strainmaster software. As with DIC, the analysis parameters were optimised via an assessment of an applied rigid body translation (in this case, a vertical movement of $20 \mu \mathrm{m}$ between successive tomographs of an unloaded specimen). For an interrogation subset of $128 \times 128 \times 128$ voxels at $75 \%$ overlap with two passes, the displacement measurement uncertainty is $2.8 \mu \mathrm{m}$. The corresponding strain error is $5 \times 10^{-4}$. Small rigid body rotations and movements of the specimens under load were removed from the measured displacement fields ${ }^{24}$. The reported displacement fields are aligned with the applied compression axis, with reference to zero displacement at the central position. 


\section{Numerical model}

A Finite Element model was developed that described the microstructure of the composite material, with cohesive properties to simulate damage development. The key microstructure features of the model are the matrix, pores and the fibre tows (Fig 1). Image-based models of composites have been developed that use segmentation of X-ray tomographs to define the positions and shapes of fibres, pores and matrix ${ }^{29}$. Due to the scale of the model required here to simulate the full specimen without using homogenisation, a mathematical description was used, which was obtained from optical images and also by inspection of a representative sample of the microstructure that had been characterised by high resolution synchrotron X-ray computed tomography ${ }^{30}$. A set of node positions in 3D space was first defined using the positions of centres along the fibre tows. After defining this basic nodal set, the mesh of tetrahedral elements was created via Delaunay triangularization using the software Paraview $3.98^{31}$. The final model has 102586 tetrahedral elements with 47151 nodes, with an average spacing of $0.6 \mathrm{~mm}$. By comparing the mesh and the defined positions of the microstructural features, individual elements were defined as matrix, fibre tows and pores with the assignment of appropriate mechanical properties. The Young's modulus of the pores was arbitrarily chosen as $0.01 \%$ of the matrix modulus. This low value reproduces the mechanical behaviour of the empty pores, relative to the solid material, whilst avoiding the numerical instability that can occur with the use of a zero modulus. The following describes the creation of the nodal set of the FE model in more detail.

The composite structure is formed of layers of vertically and horizontally oriented fibre tows (Fig 1). Their arrangement is approximated in the FE model, using dimensions obtained from optical observations, which were consistent with previously obtained synchrotron tomography data ${ }^{30}$. Each vertical fibre tow within a layer is defined using a $2 \mathrm{D}$ sinusoidal curve (equation 1) with amplitude $0.789 \mathrm{~mm}$ and wavelength $6.313 \mathrm{~mm}$ that is aligned to the $y$-direction, which describes the locus of the central axis of the fibre tow in the $x-y$ plane. The initial nodes of the mesh (Fig 3) are then defined using equations 2 to 5 and parameters $a, b$ and $c$. The combined thickness of the fibre tow and matrix in the $x$ direction is described by a linear variation between $0.789 \mathrm{~mm}$ to $2.367 \mathrm{~mm}$ over half the wavelength. Cross-sections in the $y-z$ plane at the thickest and thinnest points of the tow and matrix are shown in Figs 3a and $3 \mathrm{~b}$, and their width is describe by three columns of nodes, which are separated by a distance in the $z$ direction of $0.667 \mathrm{~mm}$. There are 4 such rows of fibre tows in the model. To describe the variation in thickness of the fibre tow, parameter $b$ has value 1 for the central column and 0.8 for the columns at either side. After introducing a horizontal fibre tow by evaluating the equations discretely, the next vertical fibre tow is inserted at a relative $y$-displacement of $1.420 \mathrm{~mm}$ by incrementing parameter $c$. Each layer of vertical fibre tows crosses the horizontal fibre tows alternately to achieve the $2.5 \mathrm{D}$ braided composite weave through parameter $a$, which alternates from 1 to -1 with consecutive layers. Each fibre tow in a vertical layer has a constant value of $z$, which is increased by $1.334 \mathrm{~mm}$ between consecutive layers. The horizontal fibre tows (Fig 1a) are created using the mesh elements that link the nodes of the vertical fibres at their peaks and valleys. The thickness of those fibre tows does not vary along their length. Finally, the large pores between the fibre tows are inserted. A comparison between the defined materials and real microstructure is shown in Fig 3d. The final mesh that simulates the specimen is illustrated in Fig 4: which shows the horizontal layers of fibre tows (Fig 4a); the four layers of vertical fibre tows (Fig 4b); the matrix (Fig 4c) and the large pores (Fig 4d). 


$$
\begin{aligned}
& x_{n}=0.789 \sin y \frac{}{6.313} \div+c \\
& x_{1}=a\left(x_{n}+0.315 b\right) \\
& x_{2}=a\left(\begin{array}{ll}
x_{n} & 0.315 b
\end{array}\right) \\
& x_{3}=a \quad x_{n}+0.394+0.789 \mid 1 \quad \text { sin } y \frac{}{6.313} \div \mid \div b \\
& x_{4}=a \quad x_{n} \quad 0.394+0.789 \mid 1 \quad \sin y \frac{}{6.313} \div \cdot \div b
\end{aligned}
$$

The numerical simulation with the created mesh was implemented as a linear elastic model in ABAQUS 6.10, with iterative runs controlled through a script written in Python 3.3 that was used to reproduce the damage behaviour of the material. The Python script introduces a cohesive law model by changing iteratively the stiffness of each element according to its damage state. The strains and stresses of all elements are extracted at every model iteration, and each element's mechanical properties are changed using its cohesive law.

$$
\sigma=[D] \cdot \varepsilon
$$

From the FE model, at every step, the strain tensor of each element is calculated, and its maximum principal strain obtained. The cohesive material law (Fig 5) uses the maximum principal strain of the element to obtain the stress value, implemented through equation 6 , using the matrix $D$ that depends on the mechanical properties. This approach is widely used in FE modelling to satisfy a relationship between stress and strain defined by a cohesive law. In this case, the calculation of $D$ varies the Young's modulus to satisfy equation 6 , which is done individually in each element of every phase of the material except for the pores, for which the Young's modulus is constant and equal to the nominal value assigned during the setup of the model. The cohesive law described in Fig 5 implies that once the critical tensile strain, $\varepsilon_{\text {crit }}$, is reached, each part of the material releases fracture energy until the final tensile strain $\varepsilon_{f t}$. The value of $\varepsilon_{f t}$ is arbitrarily considered as 3 times the critical tensile failure strain, $\varepsilon_{\text {crit }}{ }^{14}$. Compressive failure is not considered for any phase in the model, since the compressive stresses are low relative to the compressive strength.

The updated mechanical properties of the elements are reinserted into ABAQUS for the next iteration. Once the system has converged (i.e. no element needs to update its mechanical properties), the load may be increased via the boundary conditions, which are: null vertical displacements on the external surface over a width of $0.5 \mathrm{~mm}$ across the sample thickness at the bottom of the disc; and an incremental vertical displacement over the equivalent area at the top external surface. The contact area is smaller than the expected area from Hertzian contact in the experiment, but was chosen to introduce pure diametral compression loading, which describes adequately the deformation of the central region of the sample.

The absolute values of the fibre tow and matrix elastic moduli may differ from the data in Table 1, represent nominal values; i.e. the fibre modulus and tensile strength before composite fabrication, and the modulus of dense matrix. The composite fabrication process is likely to 
have degraded both the fibre strength and modulus as the microstructure of SiNO fibre is not stable at high temperatures ${ }^{32}$. Only the large porosity is explicitly inserted into the model (Fig 1d and Fig 4d). Fine porosity in the matrix will affect its modulus and there is potential for relative movement of fibres within the tows. Effective values of modulus for matrix and fibre were therefore obtained by fitting the model's bulk elastic deformation to the experimental measurements, as described in section 4. The ratio of the Young's elastic modulus of fibre tows to the matrix modulus was assumed to be constant with a value of $4: 1$ (Table 1). Both constituents were assumed to have Poisson's ratio 0.2. Following the method of Saucedo et al ${ }^{15}$ the cohesive laws implemented for the matrix and fibre tows assume linear stress/strain behavior up to the critical strain, after which there is a linear decay until the strain reaches an arbitrary value of 3 times the critical strain (Fig 5) ${ }^{14}$; at this point the material is completely damaged and unable to transfer stress. The limiting value of the cohesive law affects mostly the post peak behavior, and the simulations presented here are focused on the early stages of damage (critical strain) and so are insensitive to the chosen limit. Damage simulations with critical tensile strains of $0.001,0.0005$ and 0.000375 were examined, with the same critical strain considered for both fibre and matrix.

\section{Results and Discussion}

Example load/displacement data in several tests are shown in Fig 6a. There is a characteristic load drop (i.e. a pop-in) at around $1 \mathrm{kN}$, after which the load increases until instability at around $2 \mathrm{kN}$. The equivalent tensile stress at the disc centre is $6.6 \mathrm{MPa}$ at $1 \mathrm{kN}$, calculated using equation $7^{33}$, where $P$ is the applied load, $R$ and $t$ are the sample radius and thickness and $\alpha$ is the semi-contact angle of 0.15 radians. The average tensile stress at the peak loads is $15 \mathrm{MPa}$, which is low compared to the reported tensile strength of $80 \mathrm{MPa}$ for this material ${ }^{26}$ (Table 1); however, those data are for tensile loading parallel to the warp (i.e. $y$-direction, Fig 1), whereas in this work the tensile stress acts perpendicular to the warp (i.e. $x$-direction, Fig 1), and a lower tensile strength may be expected due to the lack of fibre reinforcement in this orientation.

$$
\sigma=\frac{P}{\pi R t}(\cos \alpha)^{3} \frac{\alpha}{\sin \alpha}
$$

An optical image of a tested specimen is shown in Fig 6b; vertical cracks between fibre tows can be observed in its centre, and closer to the anvil contact there is radial cracking of the material. The DIC analysis of the optical images provides a direct measurement of the surface displacements, from which the strain field can be obtained as the gradient. Example DIC observations at an applied load of $750 \mathrm{~N}$ from separate experiments are shown in Fig 7a; in each case at least one vertical crack can be identified by using the horizontal displacement gradients (i.e. horizontal strain). The relative horizontal displacements across crack 1 (Fig 7a) are presented in Fig $7 \mathrm{~b}$ as the applied load is increased. There is a significant change in the displacement gradient as the load increases from $685 \mathrm{~N}$ to $700 \mathrm{~N}$, at which point the crack could be visualized as a strain feature. The gradients of displacement in both the vertical and horizontal directions were assessed over a distance of $3.5 \mathrm{~mm}$ about the crack as the load was increased, which effectively measures the average strains applied to the region where the crack developed. The data for several cracks (1 to 4) are presented in Fig 7c; in each case the ratio of vertical to horizontal strain is similar $(1.0 \pm 0.3)$, increasing sharply with increasing compressive vertical strain as the horizontal strain exceeds a critical value, $\varepsilon_{\text {crit }}$, of approximately 0.001 . 
Example elastic strain fields obtained in numerical simulations of the three-dimensional weave are shown in Fig 8a. These show the heterogeneity of strain that develops due to the differences in the elastic modulus and the complex architecture of fibres, matrix and pores; higher strains develop in the matrix. An applied gauge displacement can be defined from the DIC data, using the average displacement change between two regions, here separated by a vertical gauge length of $11 \mathrm{~mm}$ (defined in Fig 7a, left). The obtained experimental relation between load and the displacement over the same gauge length is shown in Fig 8b and 8c, together with the results of the numerical simulation. The fitting of the numerical model to the mechanical test data was done in the elastic region (i.e. below $750 \mathrm{~N}$ ) by varying the magnitude of the fibre tow and matrix elastic moduli, while maintaining their constant ratio of 4:1. The obtained values for the Young's elastic moduli are $11.8 \mathrm{GPa}$ for the matrix and 47.2 $\mathrm{GPa}$ for the fibre tows; together these reproduce the experimental value for the composite in the load displacement behaviour, measured by DIC (i.e. Figure 8c). The obtained isotopic bulk modulus of $18.4 \mathrm{GPa}$ is a $28.5 \%$ lower than the value reported in table 1 (Figure $8 \mathrm{~b}$ ), which was measured with tensile load applied in the warp direction ${ }^{26}$. The deformation of the vertically compressed disc sample may be affected by a lower modulus in the horizontal direction perpendicular to the warp (Fig 1a) for which there are no available data, so a discrepancy in the fitted value of an isotropic Young's modulus is reasonable. As discussed, the individual values for the matrix and fibres are expected to be lower than the reported experimental measurements for the isolated materials (Table 1). These fitted values were then used in the numerical simulation.

The model simulation reproduces the characteristic pop-in behaviour of the experiments (Fig 8b). The pop-in load increases with the critical strain that is assigned to the model, and the numerical pop-in load is close to the experimental data for a critical failure strain of 0.001 . Both matrix and fibres are represented using the same critical strain, but simulated damage occurs predominantly in the matrix due to its relatively lower modulus, and hence higher strain, and the effect of the large pores. The average numerical peak load obtained, which is insensitive to the critical strain in the examined range, is $15 \%$ lower than the average experimental data. This is attributed to the boundary conditions used in the model. The simulation underestimates the true contact area, which will also increase as compressive damage occurs; both effects will decrease the actual tensile stress at the centre of the disc ${ }^{28}$, and so increase the applied load required to achieve the critical tensile strain. For example, increasing the semi-contact angle from 0.15 to 0.3 radians $\left(\sim 17^{\circ}\right)$ would decrease the tensile stress by $10 \%$ (equation 7$)^{33}$, so the magnitude of the contact area effect is consistent with the findings here. A more sophisticated simulation could account more accurately for the contacts between surfaces.

The horizontal displacements along the central region of the horizontal diameter are compared in Fig 9a for both the experiment and its numerical simulation; the data are averaged through the specimen thickness, and measured relative to the centre of the sample. There is a good agreement between the numerical and experimental results; as the applied load increases to $1 \mathrm{kN}$, there is a significant increase in the strain observed in the central region of the disc. The horizontal and vertical strains at the centre of the specimen were extracted from the DVC data of the tomography experiment, and also from the numerical simulations, over a gauge length of $3.5 \mathrm{~mm}$. The average applied strain at which non-linearity appears in the numerical simulations increases with the critical strain (Fig 9b), and is of a similar magnitude to that observed experimentally. The trend of the numerical simulation is 
consistent with the surface DIC observations, which is to be expected due to the fitting of the material properties. The DVC data, obtained at loads below the first pop-in, are noisy compared to the DIC data, but the displacements and average strains are consistent with the numerical model and experimentally observed surface behaviour. The agreement between surface and volumetric observations indicates that the damage development is not affected by surface preparation; whilst some surface damage may be expected, the large pores are more significant defects and are distributed through the whole sample volume.

The patterns of damage predicted by the numerical simulation are presented in Fig 10. The numerical data are shown first as a 3D visualization of the predicted damage, secondly as the maximum principal strain at the surface at the resolution of the model and then as the maximum principal strain from the 3D numerical displacement field; this is calculated at the lower resolution of the DVC characterization and compared with the experimental DIC and DVC data. Significant damage is predicted to develop within the body of the specimen, with patterns that are consistent with the experimental observations. The damage patterns are illustrated in more detail in Fig 11, which shows that at the first peak load or pop-in, microcracks in the matrix coalescence to form small vertical cracks that extend to the surface; their vertical propagation is prevented by the horizontal fibre tows. At the peak load, these vertical cracks coalesce to propagate across the full sample height. During the subsequent softening, the opening of those cracks increases until the radial cracks appear and cause the collapse of the sample; the resulting damage is quite similar to that observed in the experiments (Fig 6b).

The 3D simulation, using the experimentally measured critical tensile strain (i.e. 0.001) is shown to agree well with the experimentally observed elastic and in-elastic deformation of composite, and also the observed sequence and pattern of damage development. The cohesive element model thus provides a good description of the composite's behaviour. The properties of the matrix and fibres are obtained by fitting to match the bulk elastic modulus of the composite, and they represent the properties of the homogenized regions of material that are described by the cohesive elements.

Direct observation of surface crack nucleation provides a measure of the critical tensile strain, $\varepsilon_{c r i t}$, to initiate fracture between the fibre tows, which is approximately 0.001 (Fig 7c). The elastic properties of the three-dimensional cohesive element simulation of the specimen were then tuned to the measured bulk elastic properties, maintaining the relative ratio of matrix to fibre modulus, which allows the measured tensile critical strain to be applied to predict the development of damage. The simulation agrees well with the observed patterns of damage development (Fig 10), and the progressive change in mechanical response with increasing damage. The experimentally observed peak load is greater than that of the simulation (compare Fig 6a and Fig 8b), which can be attributed to the spreading of the contact area in the experiment that is not reproduced in the current numerical model. Simulation of contact mechanics could be introduced in future work, and might be validated by tomographic observation with suitably X-ray transparent loading anvils.

The cohesive element model applied in this work has been used to simulate the onset of failure, which occurs in the matrix due to the stress concentrations of the porosity and the geometry of the weave. The potential for debonding of weak interfaces between the matrix and fibre ${ }^{34}$ has not been included in the modeling, as this would require higher resolution and 
would also introduce further model parameters that would require fitting. At the resolution of the experimental observations and the simulation, the development of damage would be similar if debonding of the matrix/fibre interface were to be introduced, and so the obtained critical strain criteria is sufficient. More advanced numerical tools with high computational efficiency allow higher resolution simulations, which may be validated by experiments ${ }^{35}$ such as in this work.

\section{Conclusion}

A cohesive element numerical model, which reproduces the three-dimensional structure and porosity of a ceramic composite, successfully simulates the patterns of damage that are observed experimentally. Quantitative measurements of deformation by image correlation allow fitting of the elastic properties of the matrix and fibres, so the homogeneous distribution of strain is correctly simulated. Local damage nucleation and propagation can then be simulated using a tensile strain criterion, which is validated experimentally.

\section{Acknowledgements}

This work was carried out within the UK EPSRC project "QUBE: Quasi-Brittle fracture: a 3D Experimentally-validated approach" (EP/J019992/1). The authors are grateful to Ying Wang for her assistance with the X-ray tomography experiment performed at the Manchester X-ray Imaging Facility, which was funded in part by EPSRC grants EP/F007906/1, EP/F001452/1 and EP/I02249X/1. In compliance with Research Council UK policy, the data underlying this work may be obtained by contacting the corresponding author.

\section{References}

1. Katoh, Y., Snead, L.L., Henager, C.H., et al. (2007) Current status and critical issues for development of SiC composites for fusion applications. J. Nucl. Mater., 367-370, $659-671$.

2. Lee, W.E., Gilbert, M., Murphy, S.T., and Grimes, R.W. (2013) Opportunities for Advanced Ceramics and Composites in the Nuclear Sector. J. Am. Ceram. Soc., 96 (7), 2005-2030.

3. Cao, F., Fang, Z., and Zhang, C. (2013) High-temperature properties and associated structure evolution of continuous SiNO fiber-reinforced BN composites for wave transparency. Mater. Des., 43, 258-263.

4. Zou, C., Zhang, C., Xiao, Y., et al. (2012) Fabrication of high performance silicon oxynitride fibers reinforced boron nitride composites via borazine precursor infiltration and heating. J. Non. Cryst. Solids, 358 (23), 3338-3341.

5. Naslain, R. (2004) Design, preparation and properties of non-oxide CMCs for application in engines and nuclear reactors: an overview. Compos. Sci. Technol., 64 (2), $155-170$.

6. Mahadik, Y., Brown, K.A.R., and Hallett, S.R. (2010) Characterisation of 3D woven composite internal architecture and effect of compaction. Compos. Part A Appl. Sci. Manuf., 41 (7), 872-880.

7. Komeili, M., and Milani, A.S. (2012) The effect of meso-level uncertainties on the 
mechanical response of woven fabric composites under axial loading. Comput. Struct., 90-91 (1), 163-171.

8. Vanaerschot, A., Cox, B.N., Lomov, S. V., and Vandepitte, D. (2013) Stochastic multiscale modelling of textile composites based on internal geometry variability. Comput. Struct., 122, 55-64.

9. Fagiano, C., Genet, M., Baranger, E., and Ladevèze, P. (2014) Computational geometrical and mechanical modeling of woven ceramic composites at the mesoscale. Compos. Struct., 112 (1), 146-156.

10. Yang, Q., and Naderi, M. (2015) Numerical Modelling of Failure in Advanced Composite Materials, Elsevier.

11. Zhang, D., and Hayhurst, D.R. (2010) Stress-strain and fracture behaviour of $0^{\circ} / 90^{\circ}$ and plain weave ceramic matrix composites from tow multi-axial properties. Int. J. Solids Struct., 47 (21), 2958-2969.

12. Ismar, H., and Streicher, F. (1999) Modelling and simulation of the mechanical behavior of ceramic matrix composites as shown by the example of SiC/SiC. Comput. Mater. Sci., 16 (1-4), 17-24.

13. El Said, B., Ivanov, D., Long, A.C., and Hallett, S.R. (2014) Multi-scale modeling of 3D woven structures for mechanical performance. 16th Eur. Conf. Compos. Mater. ECCM 2014.

14. Saucedo-Mora, L., and Marrow, T.J. (2015) FEMME: A multi-scale Finite Element Microstructure MEshfree fracture model for quasi-brittle materials with complex microstructures. Eng. Fract. Mech., 147, 355-372.

15. Saucedo-Mora, L., Mostafavi, M., Khoshkhou, D., et al. (2016) Observation and simulation of indentation damage in a SiC-SiCfibre ceramic matrix composite. Finite Elem. Anal. Des., 110, 11-19.

16. Saucedo-Mora, L., Slámečka, K., Thandavamoorthy, U., and Marrow, T.J. (2015) Multi-scale modeling of damage development in a thermal barrier coating. Surf. Coatings Technol., 276, 399-407.

17. Kumar, R.S. (2013) Analysis of coupled ply damage and delamination failure processes in ceramic matrix composites. Acta Mater., 61 (10), 3535-3548.

18. Grujicic, M., Snipes, J.S., Galgalikar, R., et al. (2015) Multi-length-scale derivation of the room-temperature material constitutive model for $\mathrm{SiC} / \mathrm{SiC}$ ceramic-matrix composites. Proc. Inst. Mech. Eng. Part L J. Mater. Des. Appl. .

19. Hild, F., and Roux, S. (2006) Digital Image Correlation: from Displacement Measurement to Identification of Elastic Properties - a Review. Strain, 42 (2), 69-80.

20. Mostafavi, M., and Marrow, T.J. (2012) Quantitative in situ study of short crack propagation in polygranular graphite by digital image correlation. Fatigue Fract. Eng. Mater. Struct., 35 (8), 695-707.

21. Bernachy-Barbe, F., Gélébart, L., Bornert, M., et al. (2015) Anisotropic damage behavior of $\mathrm{SiC} / \mathrm{SiC}$ composite tubes: Multiaxial testing and damage characterization. Compos. Part A Appl. Sci. Manuf., 76, 281-288.

22. Chateau, C., Gélébart, L., Bornert, M., et al. (2011) In situ X-ray microtomography characterization of damage in $\mathrm{SiCf} / \mathrm{SiC}$ minicomposites. Compos. Sci. Technol., 71 (6), 
916-924.

23. Bay, B.K., Smith, T.S., Fyhrie, D.P., and Saad, M. (1999) Digital volume correlation: Three-dimensional strain mapping using x-ray tomography. Exp. Mech., 39 (3), 217226.

24. Mostafavi, M., Collins, D.M., Cai, B., et al. (2015) Yield behavior beneath hardness indentations in ductile metals, measured by three-dimensional computed X-ray tomography and digital volume correlation. Acta Mater., 82, 468-482.

25. Vertyagina, Y., Mostafavi, M., Reinhard, C., et al. (2014) In situ quantitative threedimensional characterisation of sub-indentation cracking in polycrystalline alumina. $J$. Eur. Ceram. Soc., 34 (12), 3127-3232.

26. Zou, C., Zhang, C., Li, B., et al. (2015) Fabrication and properties of borazine derived boron nitride matrix wave-transparent composites reinforced by 2.5 dimensional fabric of Si-N-O fibers. Mater. Sci. Eng. A, 620, 420-427.

27. Zou, C., Marrow, T.J., Reinhard, C., et al. (2016) Porosity characterization of fiberreinforced ceramic matrix composite using synchrotron X-ray computed tomography. $J$. Instrum., 11 (3), C03052.

28. Awaji, H., and Sato, S. (1979) Diametral Compressive Testing Method. J. Eng. Mater. Technol. Trans. ASME, 101 (2), 139-147.

29. Straumit, I., Lomov, S. V, and Wevers, M. (2015) Quantification of the internal structure and automatic generation of voxel models of textile composites from X-ray computed tomography data. Compos. Part A Appl. Sci. Manuf., 69, 150-158.

30. Zou, C., Marrow, T.J., Reinhard, C., et al. (2015) Pore structure analysis of fiberreinforced ceramic matrix composite using synchrotron X-ray computed tomography. Symp. Multi-scale Multi-Dimensional Synchrotron Radiat. Imaging.

31. Ayachit, U. (2015) The ParaView Guide: A Parallel Visualization Application, Kitware.

32. Sato, M., and Okamura, K. (1998) Manufacturing and high temperature mechanical properties of Si-N-O ceramic fibers. Nippon Seramikkusu Kyokai Gakujutsu Ronbunshi/Journal Ceram. Soc. Japan, 106 (3), 248-255.

33. Wang, Q.., Jia, X.., Kou, S.., et al. (2004) The flattened Brazilian disc specimen used for testing elastic modulus, tensile strength and fracture toughness of brittle rocks: analytical and numerical results. Int. J. Rock Mech. Min. Sci., 41 (2), 245-253.

34. Zhang, C., Zhao, M., Liu, Y., et al. (2016) Tensile strength degradation of a 2.5DC/SiC composite under thermal cycles in air. J. Eur. Ceram. Soc., 36 (12), 3011-3019.

35. Saucedo-Mora, L., and Marrow, T.J. (2016) Multi-scale damage modelling in a ceramic matrix composite using a finite-element microstructure meshfree methodology. Philos. Trans. R. Soc. London A Math. Phys. Eng. Sci., 374 (2071).

36. Zou, C., Zhang, C., Li, B., et al. (2015) Ablation behavior of boron nitride based ceramic composites reinforced by continuous silicon oxynitride fiber. Ceram. Int., $\mathbf{4 1}$ (3), 4768-4774.

37. Paine, R.T., and Narula, C.K. (1990) Synthetic routes to boron nitride. Chem. Rev., 90 (1), 73-91. 
38. Eichler, J., and Lesniak, C. (2008) Boron nitride (BN) and BN composites for hightemperature applications. J. Eur. Ceram. Soc., 28 (5), 1105-1109. 
Table 1: Mechanical properties of the SiNO fibres, BN matrix and the full $\mathrm{SiNO}_{\mathrm{f}} / \mathrm{BN}$ composite. The composite's data are for tensile load applied in the warp direction.

\begin{tabular}{|c|c|c|}
\hline & $\begin{array}{l}\text { Young Modulus } \\
(\mathrm{GPa})\end{array}$ & $\begin{array}{l}\text { Tensile strength } \\
(\mathrm{MPa})\end{array}$ \\
\hline SiNO Fibres 32,36 & $78 \pm 6.5$ & $1400 \pm 126$ \\
\hline BN Matrix ${ }^{37,38}$ & 20 to 45 & 20 to 120 \\
\hline $\mathrm{SiNO}_{\mathrm{f}} / \mathrm{BN}$ Composite ${ }^{26}$ & $25.7 \pm 2.3$ & $78.3 \pm 7.1$ \\
\hline
\end{tabular}

a)

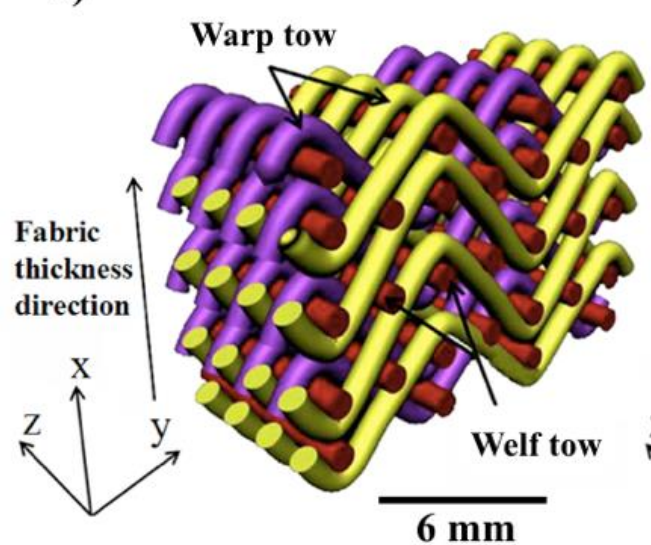

c)

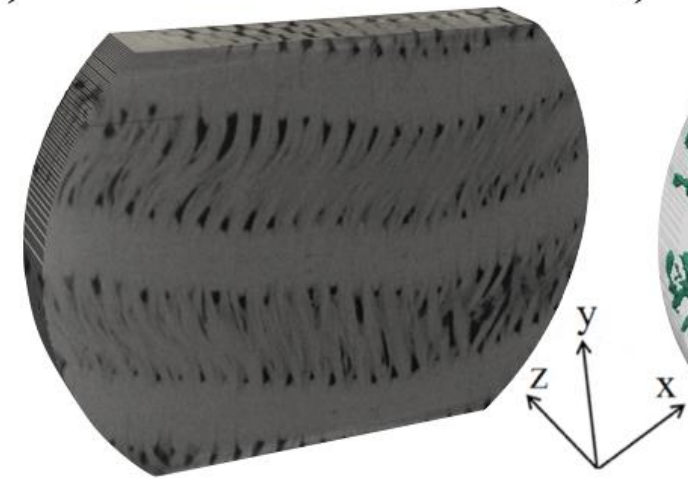

b)

d)
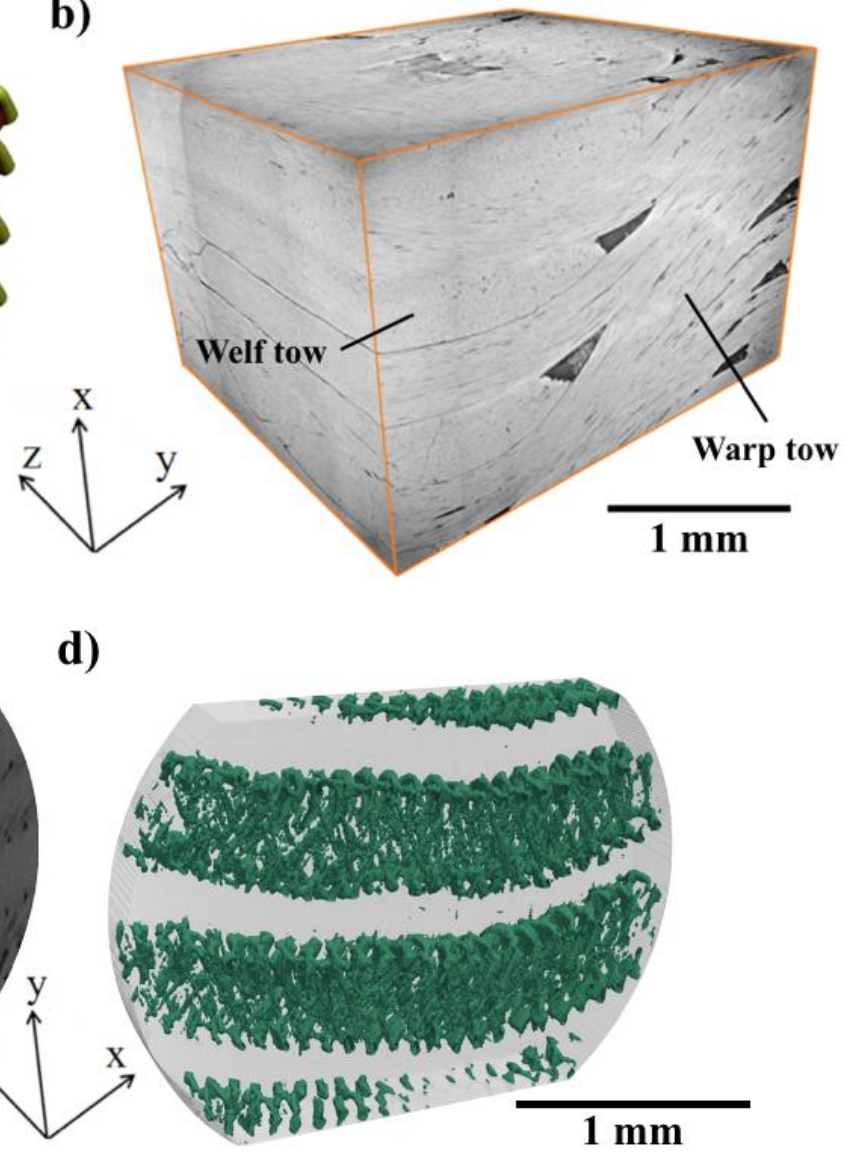

Fig 1: The $\mathrm{SiNO}_{\mathrm{f}} / \mathrm{BN}$ ceramic matrix composite: a) 2.5 dimensional fabric architecture and the coordinate system used in the present study; b) Synchrotron X-ray tomography image of the microstructure (porosity is dark) ${ }^{27}$; c) Laboratory X-ray tomography of the central region of the sample; d) the macroscopic porosity of the sample, extracted from c). 
a)

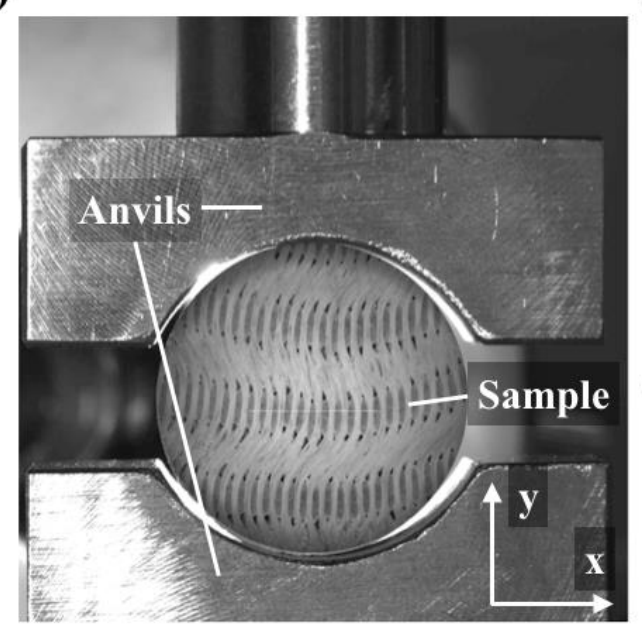

b)

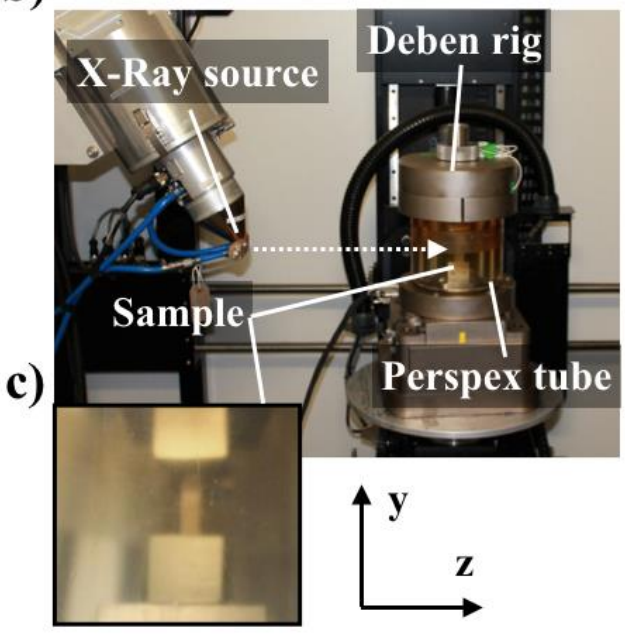

Fig 2: Diametral compression testing of the composite ceramic specimens (diameter $\sim 23 \mathrm{~mm}$ ): a) optical observation of the $x$ $y$ surface of a specimen between the steel anvils; b) the loading rig mounted on the X-ray computed tomography system - the rig was moved closer to the source for the observations; c) the specimen viewed through the Perspex tube.

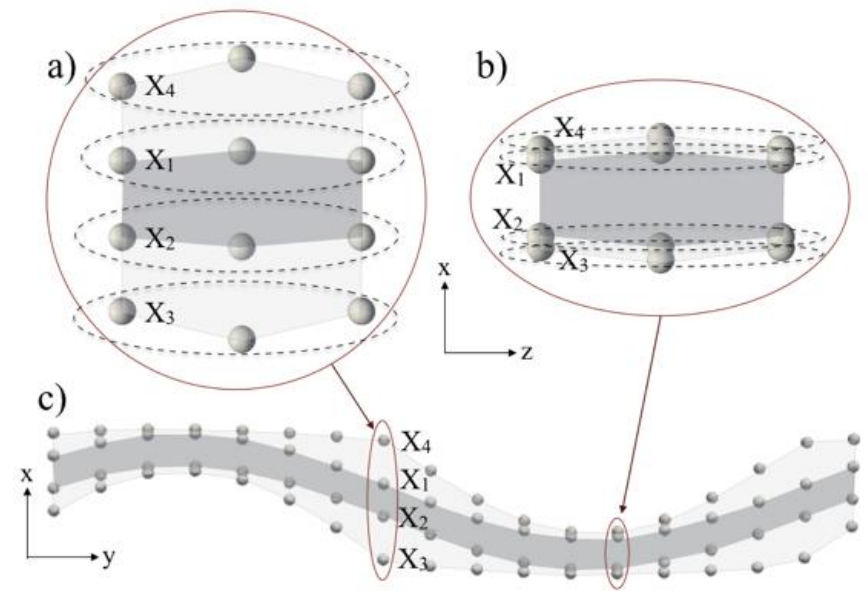

d)

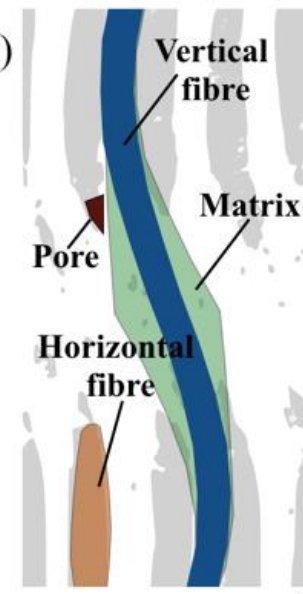

e)

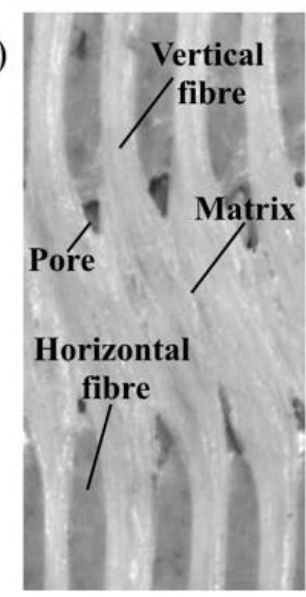

$2 \mathrm{~mm}$

Fig 3: Scheme of the nodes of the model that discretize the different material phases: a) and b) are cross-sections of a warp fibre tow, which is shown in c); d) and e) show a comparison of the geometry of the features in the mesh d) and the real material (optical image) e). 

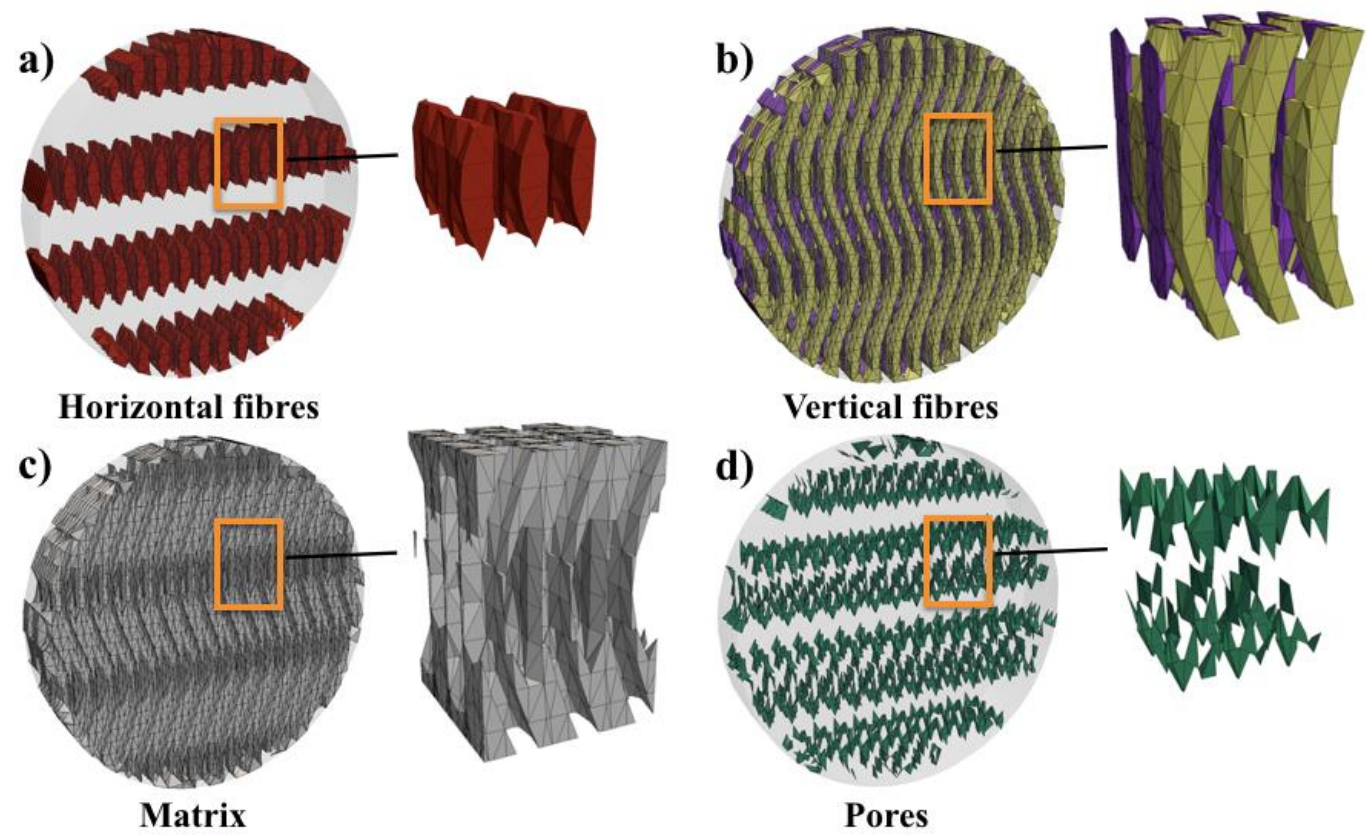

e)

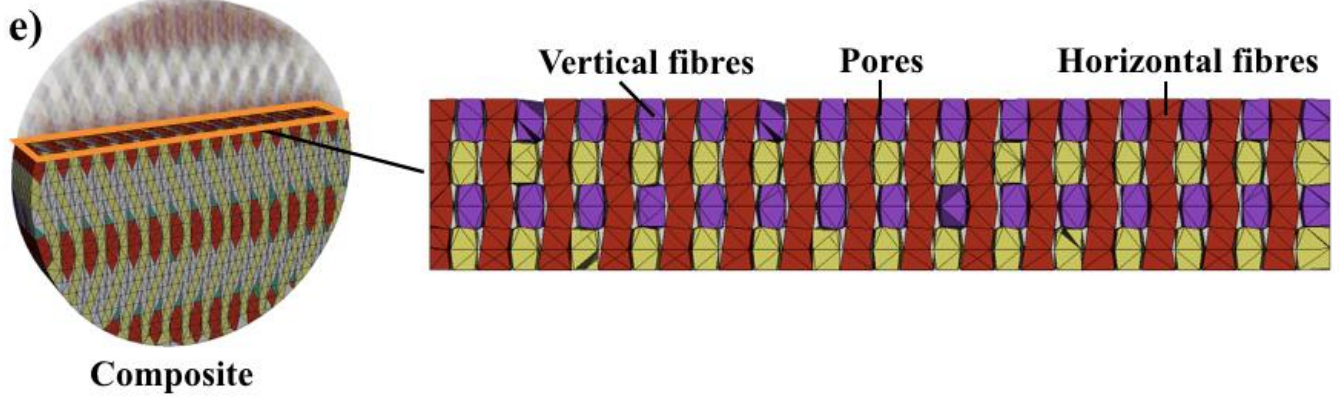

Fig 4: Mesh used for the model. The different features are indiviually represented: a) the horizontal fibre tows; b) the vertical fibre tows; c) the matrix; d) the pores and e) the final composite and a horizontal cross section.

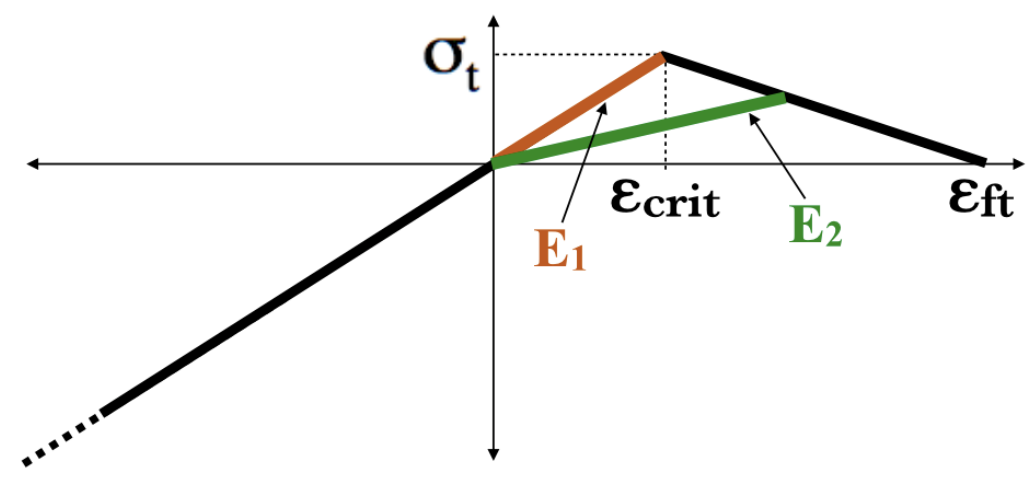

Fig 5: The general form of the cohesive material law, where $\sigma_{t}$ is the tensile strength; $\varepsilon_{c r i t}$ is the critical strain and $\varepsilon_{f t}$ is the final strain. The Figure shows the initial elastic Young's Modulus $E_{1}$ and an equivalent Young's Modulus $E_{2}$ used to relate the stress to a particular strain during the cohesive fracture process. 
a)

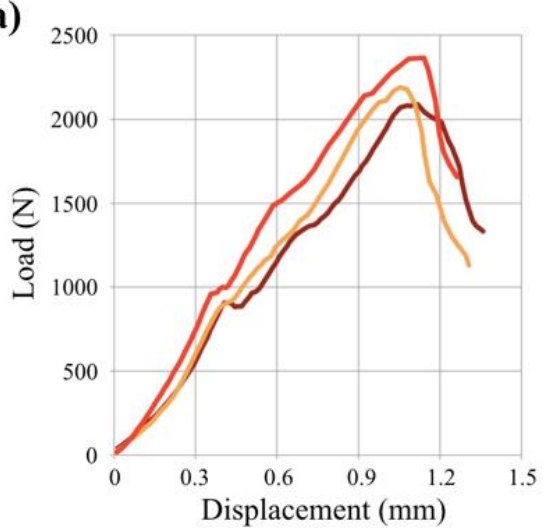

b)

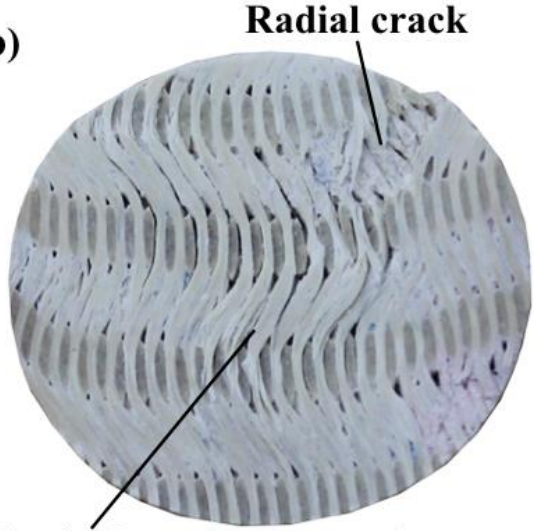

Vertical crack
$5 \mathrm{~mm}$

Fig 6: Experimental diametral compression test data: a) example load/displacement data from three independent diametral compression tests. The reported displacement is the relative movement of the Shimadzu mechanical test frame crosshead; b) optical observation of the surface of a tested sample (after peak load). Vertical cracking and radial cracking are indicated.

a)

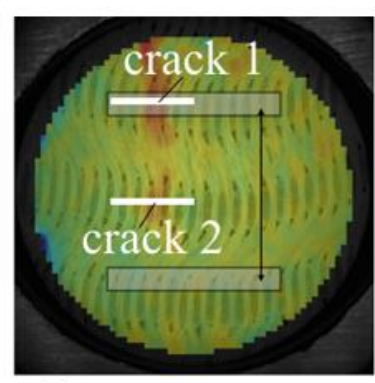

$5 \mathrm{~mm}$
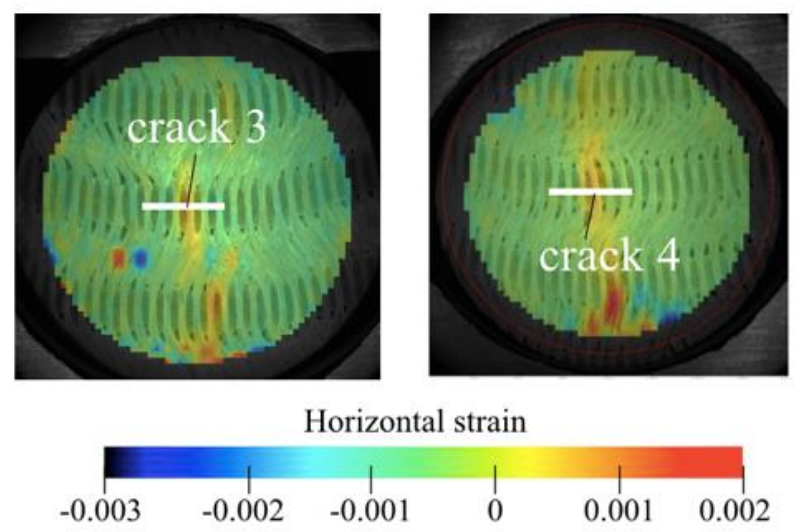

b)

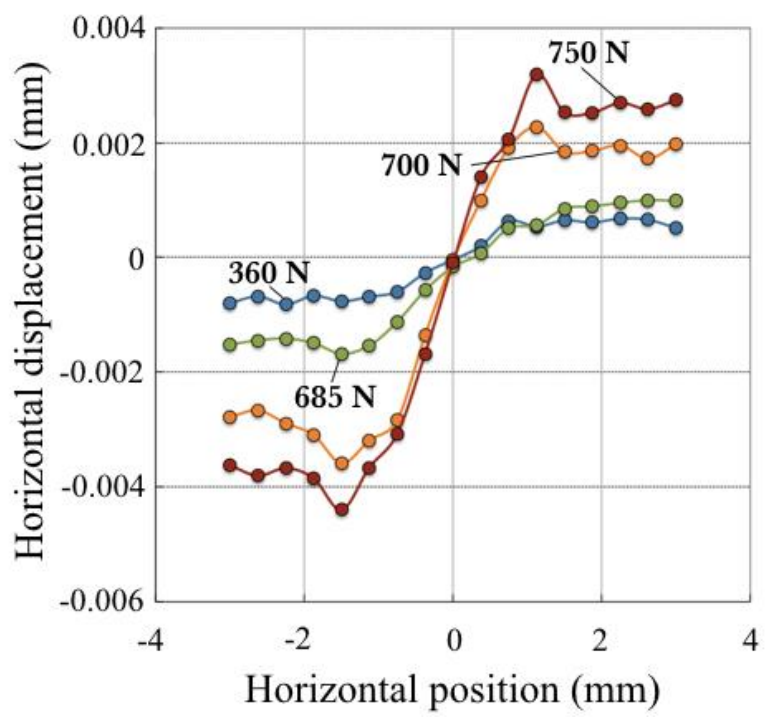

c)

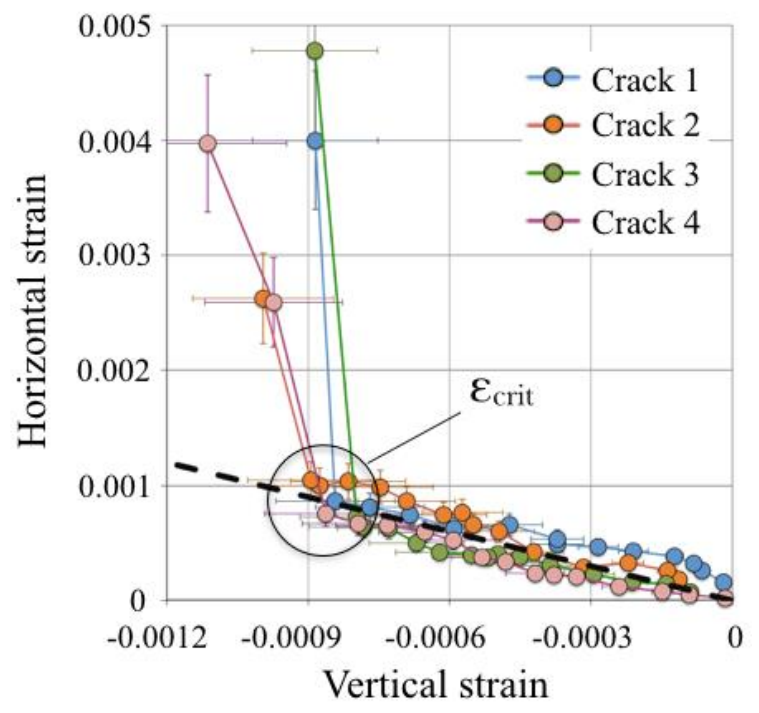

Fig 7: a) Digital Image Correlation analysis of 3 specimens, observed under load at $750 \mathrm{~N}$, relative to the small preload (10 $\mathrm{N}$ ). The developed cracks are identified using the horizontal strain field. The grey rectangles in (a) show the positions that 
are used to measure the change in displacement across a vertical gauge length; b) the variation of relative horizontal displacement across the position of crack 1 with increasing applied load; and c) the relationship between the vertical and horizontal strains measured within a square of $3.5 \times 3.5 \mathrm{~mm}$ around each crack's location. The critical horizontal strain $\left(\varepsilon_{\text {crit }}\right)$, at which the horizontal strain increases sharply with compressive vertical strain, is 0.0004 to 0.001 (average 0.0008 ).

a) $205 \mathrm{~N}$

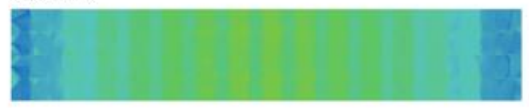

$580 \mathrm{~N}$

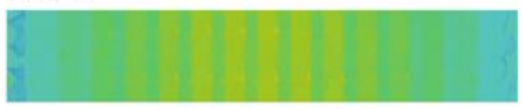

$895 \mathrm{~N}$

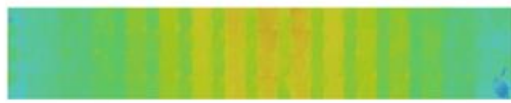

\section{$1100 \mathrm{~N}$}

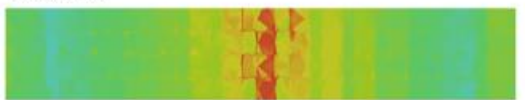

$1521 \mathrm{~N}$

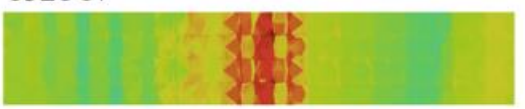

Collapse

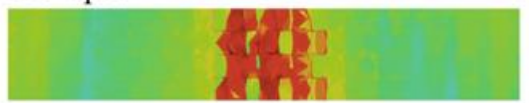

Maximum principal strain

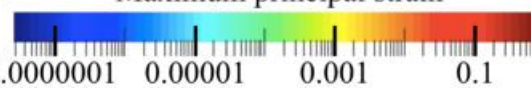

b)

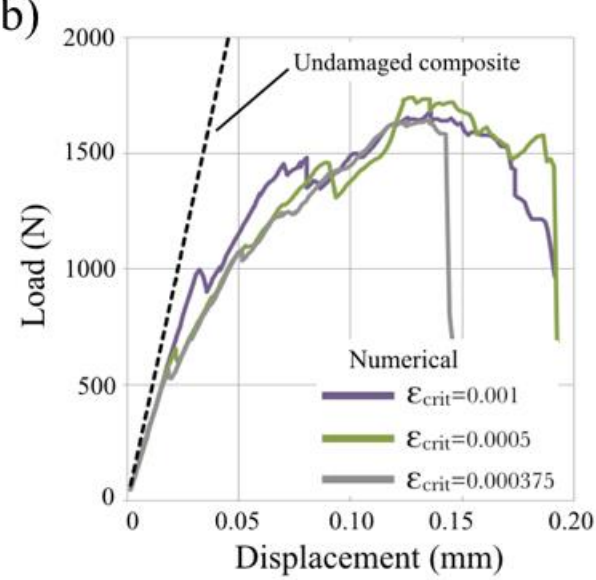

c)

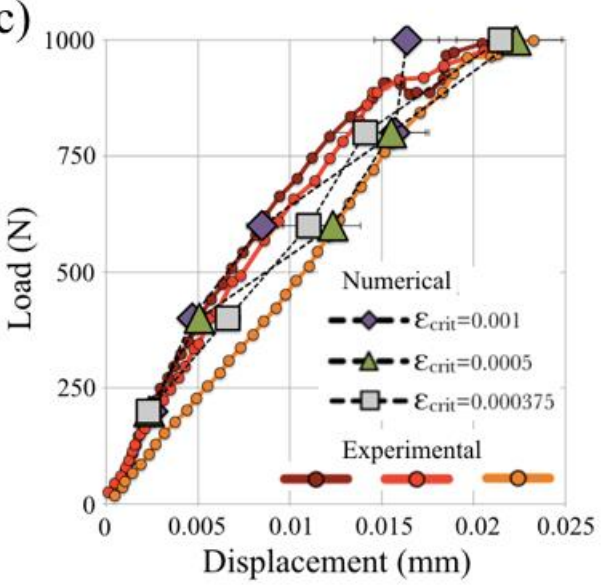

Fig 8: a) Examples of the elastic strain fields at the central horizontal $x-z$ section of the numerically simulated test specimen (dimension is $24 \times 4 \mathrm{~mm}$ ) for a critical strain of 0.001 , b) numerical load-displacement curve with the imposed displacement across the disc diameter for simulations with different critical strains, and the elastic behavior of the undamaged composite with the properties of Table 1 and c) comparison of the vertical displacements measured and simulated over a vertical gauge length of $3.5 \mathrm{~mm}$ at the disc centre, also for different critical strains. 

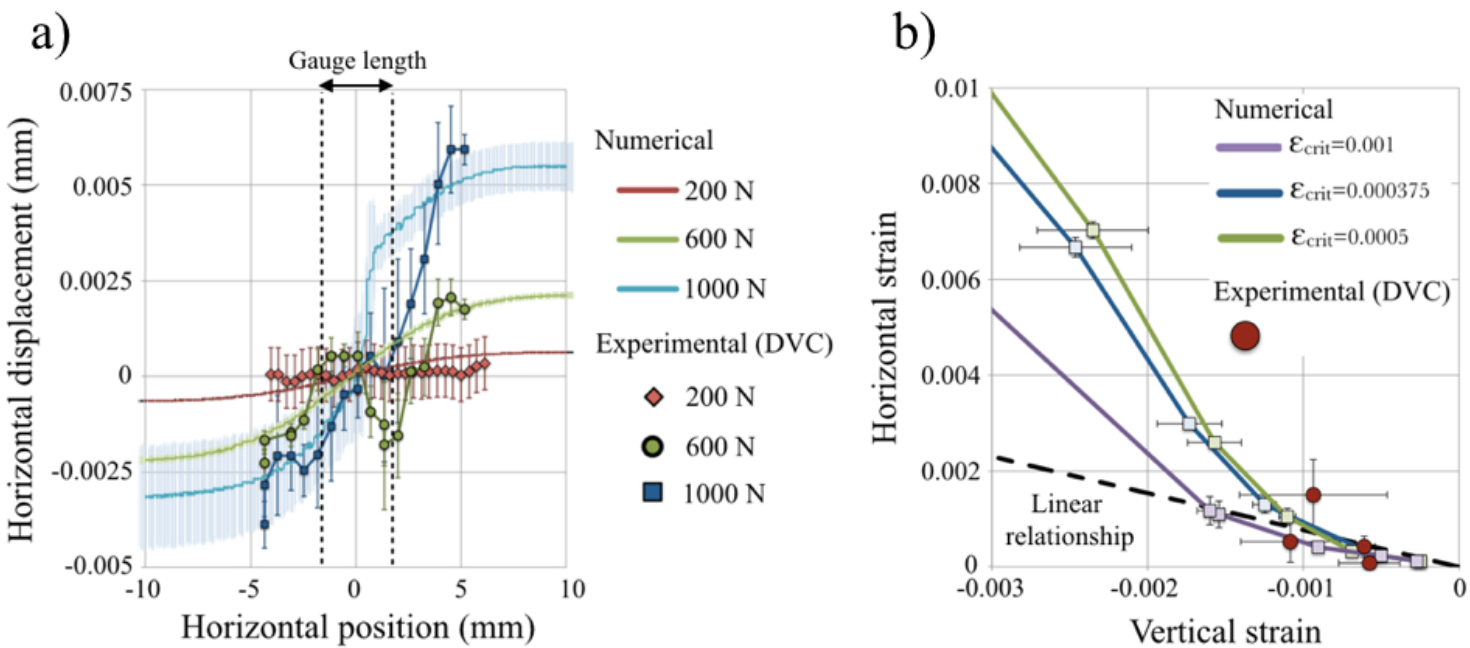

Fig 9: Digital Volume Correlation analysis of the sample loaded at $400 \mathrm{~N}$, and the comparison between the DVC and numerical results. a) horizontal displacements along the horizontal diameter, and b) the relationship between the horizontal and vertical strains measured over a central gauge length of $3.5 \times 3.5 \mathrm{~mm}$, compared with the linear relation obtained from surface DIC observations (i.e. from Fig 7c).

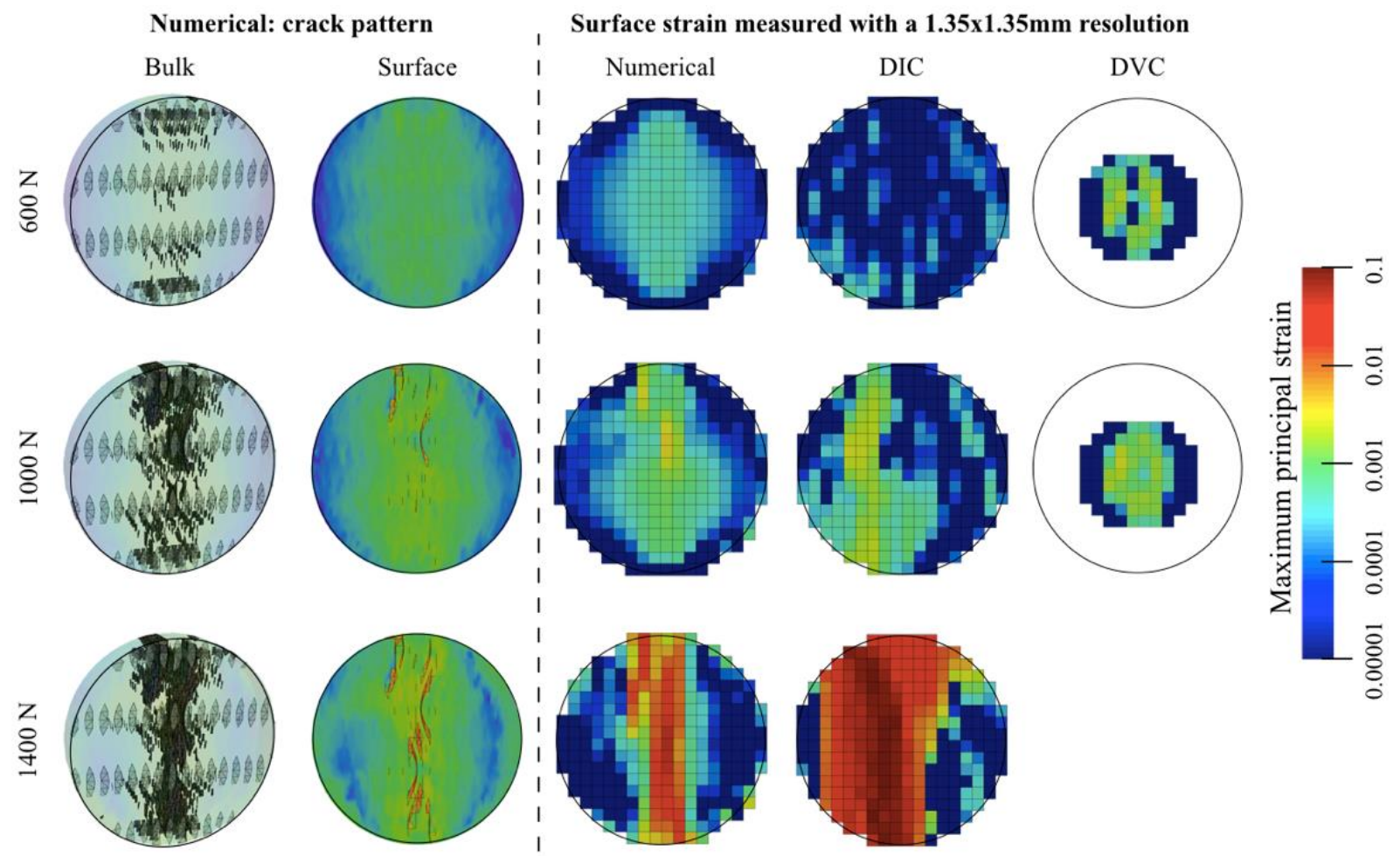

Fig 10: Comparison of the strain field and crack pattern of the numerical simulation with DIC observations of a specimen surface and DVC analysis of the in situ tomography test. The critical strain in the simulation is 0.001 . 
1st peak

a)

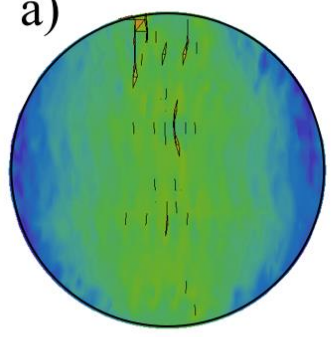

b)

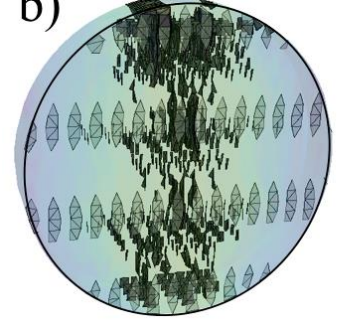

Peak load
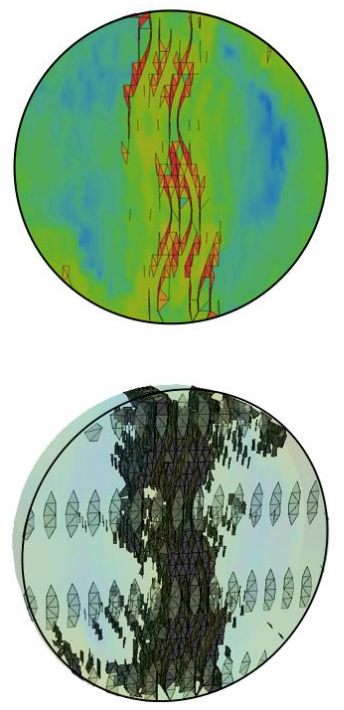

Collapse

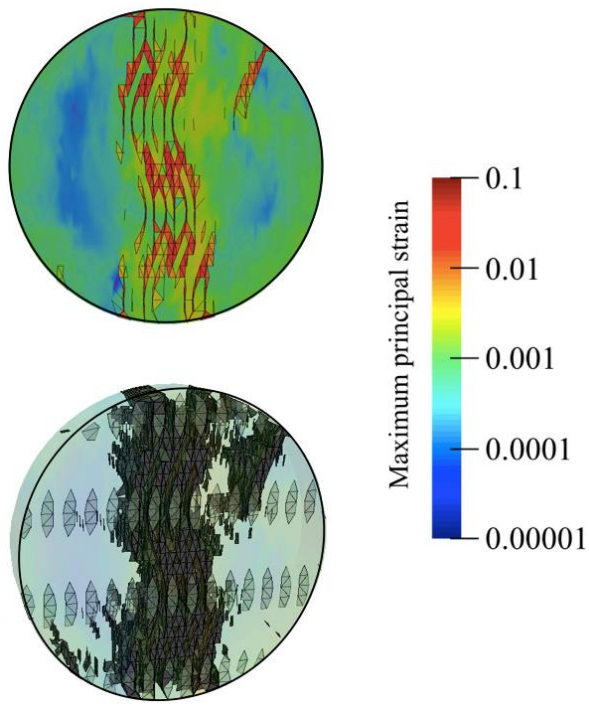

Fig 11: Numerical simulations at the first peak (i.e. pop-in), peak load and the collapse of the sample, showing a) the numerical strain field and b) the damage distribution in the microstructure. The critical strain in the simulation is 0.001 . 